\title{
Thrombotic jamming of a tricuspid prosthesis
}

\author{
M. V. J. Raj, V. Srinivas, and D. W. Evans \\ From the Regional Cardiac Unit, Papworth Hospital, Papworth Everard, Cambridge
}

This report describes malfunction of a BjörkShiley (tilting disc) prosthesis in the tricuspid situation and the usefulness of echocardiography in its detection.

\section{Case report}

The patient, a married woman, underwent closed mitral valvotomy for rheumatic mitral stenosis at the age of 45 years. Nine years later she developed disabling effort dyspnoea, recurrent ankle swelling, and excessive tiredness. She was found to have mitral re-stenosis and tricuspid valve disease. The mitral valve was replaced with a $27 \mathrm{~mm}$ BjörkShiley (tilting disc) prosthesis and the tricuspid valve with a $31 \mathrm{~mm}$ Björk-Shiley prosthesis. Warfarin was continued. Twelve months later she complained of breathlessness on slight exertion, bilateral ankle swelling, and excessive tiredness. These features persisted in spite of digoxin and intensive diuretic therapy.

Examination revealed elevation of the jugular venous pressure $(4 \mathrm{~cm}$ above sternal angle) with a slow ' $y$ ' descent. There was peripheral cyanosis and bilateral ankle oedema. Right brachial blood pressure was $150 / 90 \mathrm{mmHg}(20 \cdot 0 / 12 \cdot 0 \mathrm{kPa})$. Atrial fibrillation was established, the resting ventricular rate being about $70 / \mathrm{min}$. A long mid-diastolic rumble was audible in the tricuspid area. The prosthetic opening and closing clicks sounded normal in the mitral area but diminished in the tricuspid area. The tender liver was palpable three finger breadths below the costal margin.

Chest $x$-ray showed moderate cardiac enlargement with tricuspid and mitral prostheses in evidence.

Electrocardiogram confirmed atrial fibrillation and showed a ventricular rate of about $70 / \mathrm{min}$, with digitalis effect.

A phonocardiogram confirmed the presence of a long mid-diastolic murmur in the tricuspid area.
The opening and closing clicks of the tricuspid prosthesis were not clearly recorded but those of the mitral prosthesis were normal.

\section{Echocardiograms (Fig. 1A and B)}

An echocardiogram from the tricuspid prosthesis showed multiple abnormal echoes in the region of the disc with limitation of disc excursion (D-E = $10 \mathrm{~mm}$ ); the normal for a $31 \mathrm{~mm}$ Björk-Shiley valve is $25 \mathrm{~mm}$. The echogram from the mitral prosthesis was normal.

\section{Cardiac catheterization (Fig. 2)}

Simultaneous right atrial (RA) and right ventricular (RV) pressure traces showed an end-diastolic gradient of $17 \mathrm{mmHg}(2.3 \mathrm{kPa})$ across the tricuspid prosthesis with right atrial hypertension (20/17 $\mathrm{mmHg}(2 \cdot 7 / 2.3 \mathrm{kPa})$ ). Contrast injected into the right atrium showed this chamber to be dilated and its emptying delayed.

\section{Operative findings}

Surgical exploration of the tricuspid site was undertaken in May 1975. The Björk-Shiley disc was found to be held in the almost fully closed position by extensive thrombotic pannus on its atrial and ventricular surfaces (Fig. 3).

\section{Discussion}

The diagnosis of obstruction to the tricuspid prosthesis was suggested by the slow ' $y$ ' descent in the jugular venous pulse, long tricuspid middiastolic rumble, and diminished intensity of the tricuspid prosthetic sounds. An echogram from the tricuspid prosthesis showed abnormal multiple echoes from the region of the disc, compatible with the presence of thrombus on its surface. The echocardiographic disc excursion was found to be 


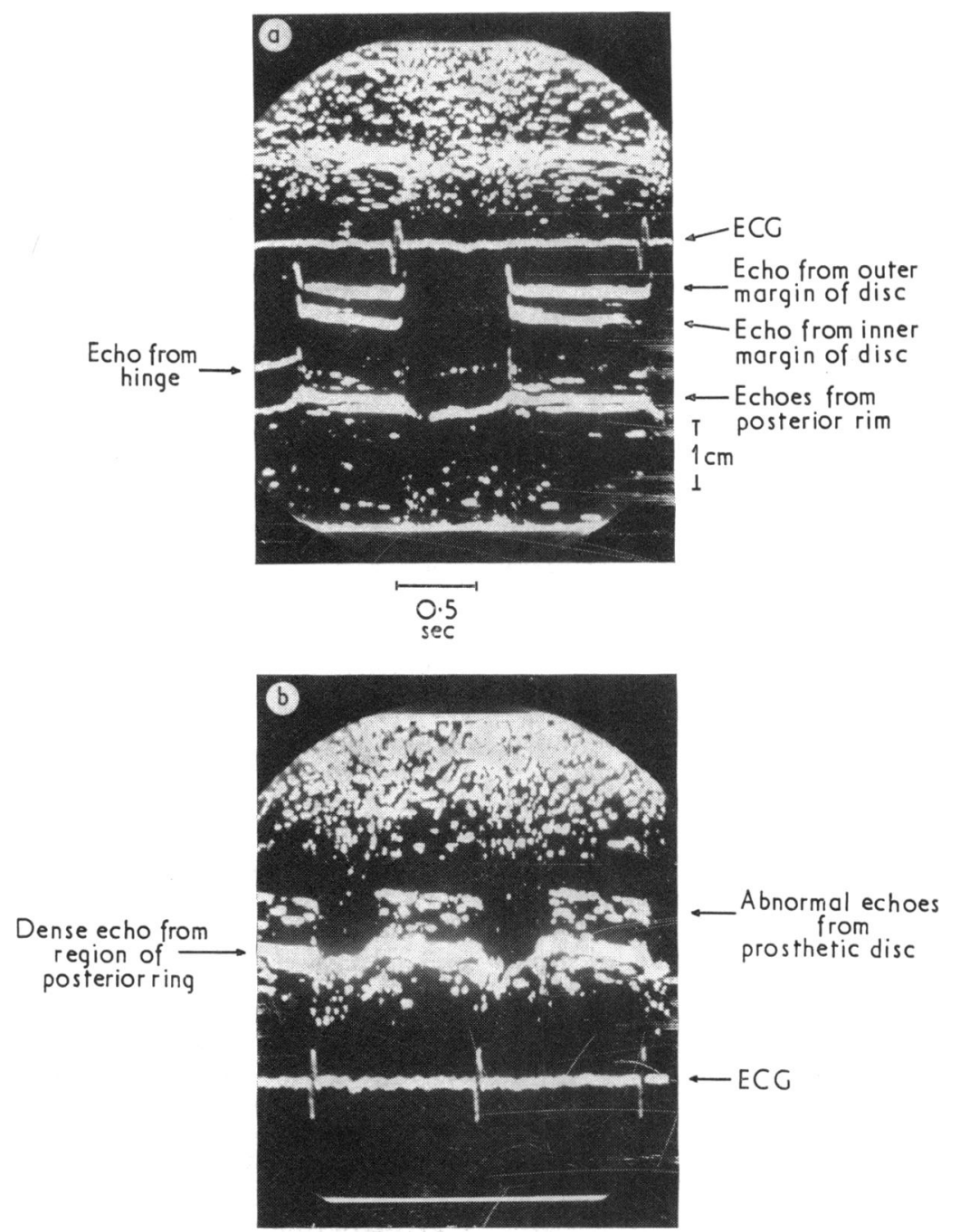

FIG. 1 (a) Echogram of the mitral Björk-Shiley $(27 \mathrm{~mm})$ prosthesis showing normal features: $D-E=25 \mathrm{~mm}, Q R S$ to ' $C$ ' point $=40 \mathrm{~ms}$; with disc opening (D-E) and closing movement $(A C)$ being normal. (b) Echogram of the tricuspid Björk-Shiley (31 mm) prosthesis showing abnormal echoes in the region of the disc, its reduced mobility $(D-E=10 \mathrm{~mm})$ and delayed closure ( $Q R S-' C$ ' point $=140 \mathrm{~ms})$.

reduced from the normal $25 \mathrm{~mm}$ to $10 \mathrm{~mm}$. Cardiac catheterization and cardioangiography provided confirmatory evidence before excision of the malfunctioning prosthesis and its replacement with a biological valve.

Thrombotic jamming of a Björk-Shiley prosthesis in the tricuspid situation has not hitherto been reported. However, Samaan and Murali (1970), Vander Veer et al. (1971), and Bache et al. (1972) have documented the occurrence of life-threatening obstruction of Starr-Edwards' valves at this site in 9 patients. Obstruction became critical between 1 and 6 years after operation. A predisposing factor was considered to be present in every case, most commonly impingement on the right ventricular endomyocardium or secondary infection.

In this case a disc prosthesis became critically obstructed within 12 months in spite of well- 


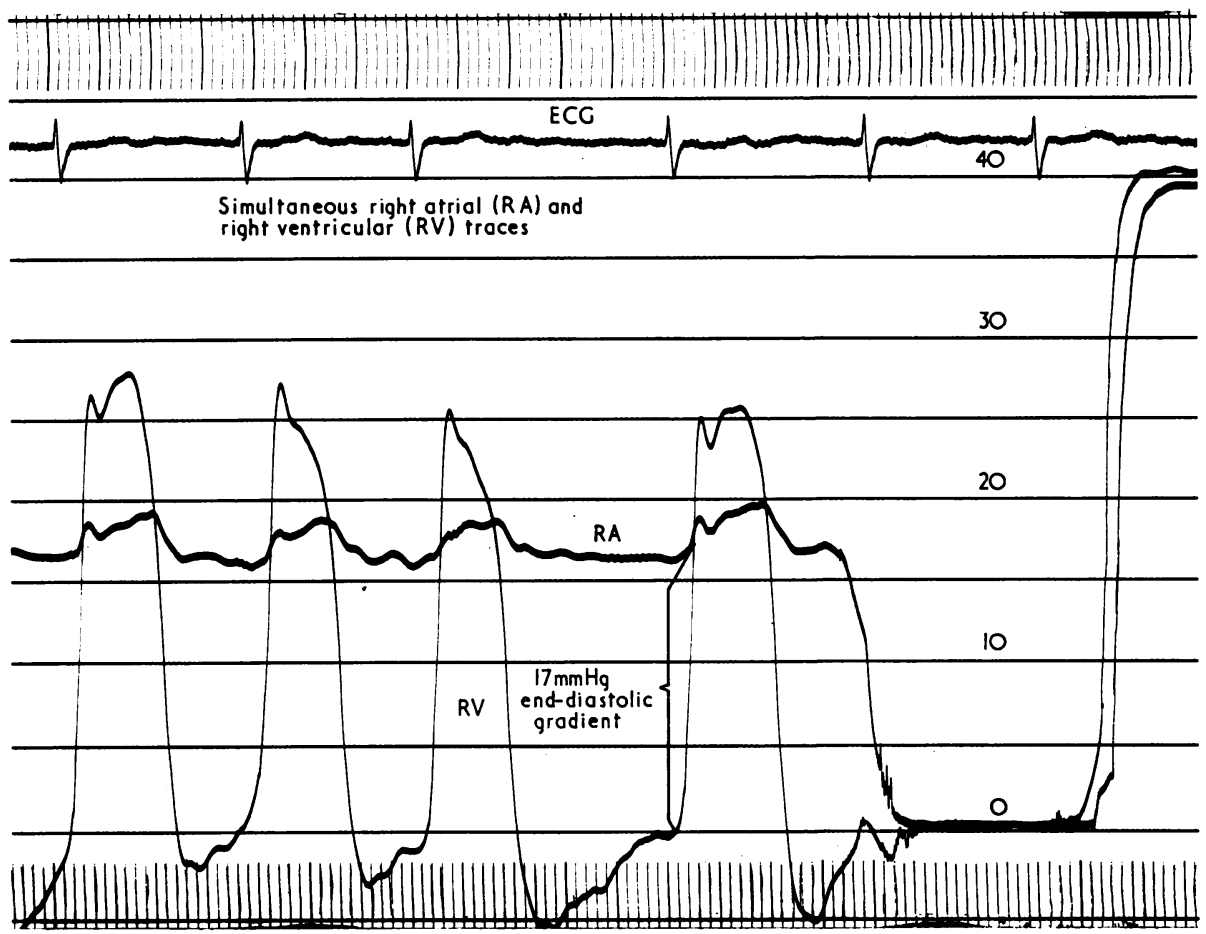

FIG. 2 Simultaneous right ventricular $(R V)$ and right atrial $(R A)$ pressure traces showing end-diastolic gradient across tricuspid prosthesis.

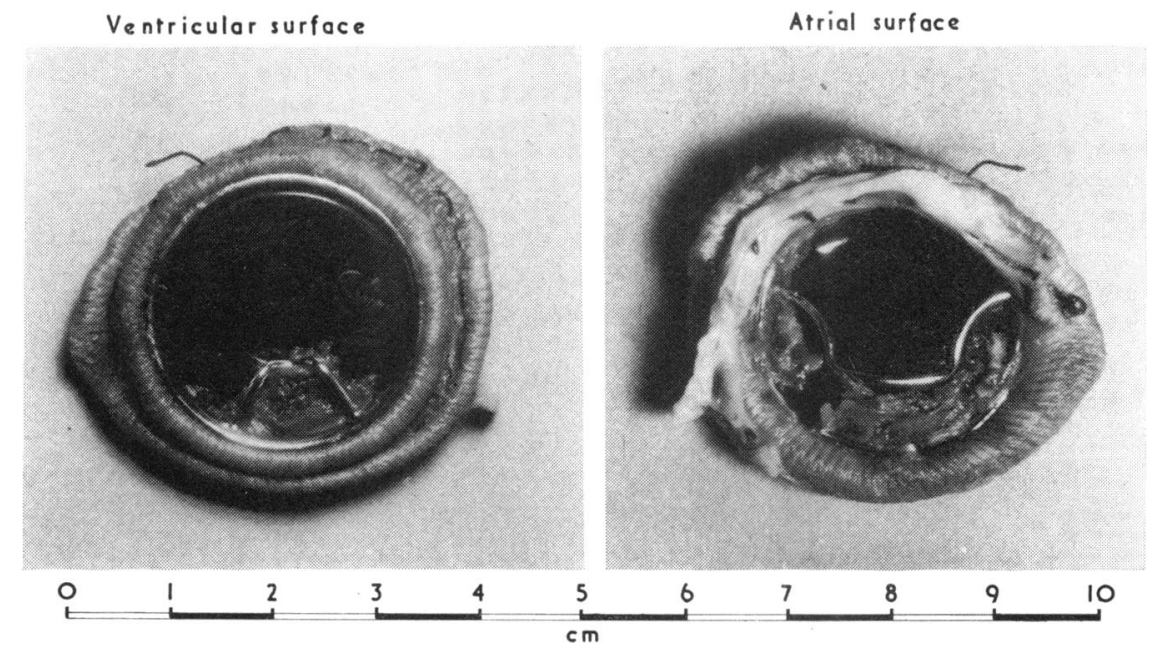

FIG. 3 Removed Björk-Shiley prosthesis showing thrombus on the atrial and ventricular surfaces of the disc. 
controlled warfarin therapy and in the absence of any definable predisposing factor.

We thank Mr. B. B. Milstein for surgical help and permission to publish this case report.

\section{References}

Bache, R. J., From, A. H. L., Castaneda, A. R., Jorgensen, C. R., and Wang, Y. (1972). Late thrombotic obstruction of Starr-Edwards tricuspid valve prosthesis. Chest, 61, 613.
Samaan, H. A., and Murali, R. (1970). Acute tricuspid valve obstruction following the use of tricuspid ball valve prosthesis. Thorax, 25, 334.

Vander Veer, J. B., Jr., Rhyneer, G. S., Hodam, R. P., and Kloster, F. E. (1971). Obstruction of tricuspid ball-valve prostheses. Circulation, 43, Suppl. 1, 62.

Requests for reprints to Dr. M. V. J. Raj, Regional Cardiac Unit, Papworth Hospital, Papworth Everard, Cambridge CB3 8RE. 